\title{
Liver transplantation for neotropical polycystic echinococcosis caused by Echinococcus vogeli: a case report
}

\author{
Tércio Genzini ${ }^{[1]}$, Nilton Ghiotti de Siqueira ${ }^{[1]}$, Huda Maria Noujaim ${ }^{[1]}$, \\ Regina Gomes dos Santos ${ }^{[1]}$, Eduardo Tomohissa Yamashita ${ }^{[1]}$, \\ Alisson Paulino Trevizo ${ }^{[1]}$ and Marcelo Perosa ${ }^{[1]}$
}

[1]. Grupo HEPATO, Hospital Bandeirantes, São Paulo, SP.

\begin{abstract}
Neotropical polycystic echinococcosis (NPE) is a parasitic disease caused by cestodes of Echinococcus vogeli. This parasite grows most commonly in the liver, where it produces multiples cysts that cause hepatic and vessel necrosis, infects the biliary ducts, and disseminates into the peritoneal cavity, spreading to other abdominal and thoracic organs. In cases of disseminated disease in the liver and involvement of biliary ducts or portal system, liver transplantation may be a favorable option. We present a report of the first case of liver transplantation for the treatment of advanced liver NPE caused by E. vogeli.
\end{abstract}

Keywords: Polycystic echinococcosis. Echinococcus vogeli. Liver transplantation.

\section{INTRODUCTION}

Echinococcosis or hydatidosis is an infection caused by cestodes of the Echinococcus genus. The species Echinococcus vogeli is responsible for polycystic echinococcosis (PE) and is restricted to Central and South America, mainly in the Amazon region ${ }^{1-4}$. In 2007, Brazil had 99 cases of PE, making it the country with the highest incidence of the disease $(58 \%$ of all cases $)^{3}$. The lifestyle of infected patients, which involves hunting of the Lowland Paca (an intermediate host), leads to the accidental introduction of human beings into the parasite's lifecycle. The E. vogeli metacestode develops most commonly in the liver, producing cysts that may be solitary or confluent.

After liver proliferation, the parasite may disseminate into the peritoneal cavity and reach other abdominal and thoracic organs. Infection by $E$. vogeli is chronic, and the most frequent signs and symptoms are abdominal pain, palpable abdominal masses, weight loss, hepatomegaly, jaundice, anemia, fever, and hemoptysis in cases involving lung impairment. Portal hypertension and obstruction of the biliary ducts are frequent and can occur in up to $25 \%$ of patients 5 . Surgical resection is a good option in the absence of advanced disease progression, mainly in the biliary ducts and in the portal system, or in the absence of diffuse liver disease ${ }^{6}$. In these cases, the fatality rate is higher and treatment by surgical resection may be accompanied by high mortality rates. In cases involving other species of Echinococcus where advanced disease progression

Address to: Dr. Eduardo Tomohissa Yamashita. Av. Dr. Altino Arantes 1300/124, Vila Clementino, 04042-005 São Paulo, SP, Brasil.

Phone: 5511 7647-2814; 5511 2276-0905

e-mail: edutomo@gmail.com; e.yama@terra.com.br

Received in 02/06/2012

Accepted in 13/08/2012 impeded resection, liver transplantation (LT) has provided good results $^{7-9}$. Here, we report the first case of LT used for treating PE caused by E. vogeli.

\section{CASE REPORT}

The patient was a 48-year-old male born in Manoel Urbano (State of Acre), where he lived until 17 years of age, and had since resided in Rio Branco, capital of the State of Acre. A physical examination revealed that his liver was palpable $7 \mathrm{~cm}$ from the right costal margin and had an irregular surface and hardened consistency, and was painless upon palpation. Computed tomography (CT) of his abdomen revealed multiple diffuse cysts on the liver with peripheral calcifications, which affected the hepatic hilum and left and right hepatic lobes (Figure 1). Laboratory diagnosis by western blotting revealed a positive serology test result for Echinococcus spp., which confirmed, together with the patient's epidemiological history (he lived on a rubber plantation where he hunted and raised dogs) the suspicion of PE. He began clinical treatment with albendazole at $10 \mathrm{mg} / \mathrm{kg} / \mathrm{day}$, but after 2 years of treatment, he began to experience multiple episodes of cholangitis, with a

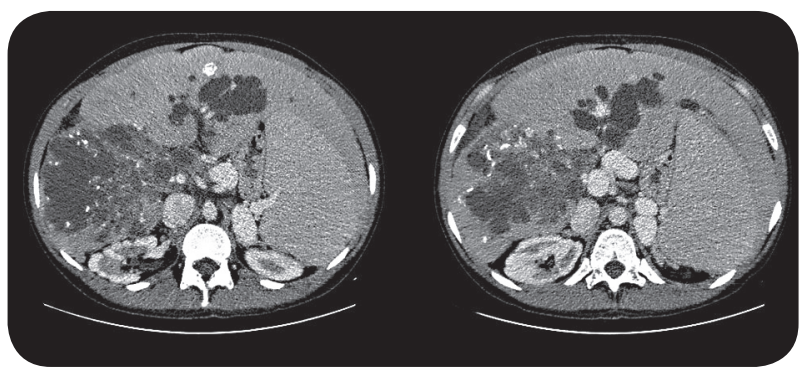

FIGURE 1 - Abdominal computed tomography scan showing multiple diffuse cysts in the liver with peripheral calcifications, affecting the hepatic hilum and both hepatic lobes. 
Model for End-Stage Liver Disease (MELD) score of 25 and direct bilirubin levels of $17.9 \mathrm{mg} / \mathrm{dL}$. Diffuse liver impairment prevented biliary drainage and a possible resection, and his case was forwarded for LT. Despite the advanced disease state, which led the patient to receive a special status on the LT waitlist, the overall clinical picture and the patient's hepatic function remained stable, with biliary obstruction and recurrent cholangitis as the main indications for LT. Intraoperative examination showed multiple cysts on the liver, occupying the right and left hepatic lobes and the hepatic hilum (Figures 2 and 3). The albendazole treatment regimen of $400 \mathrm{mg}$ twice a day was maintained in the postoperative (PO) period. Initial immunosuppression was done with tacrolimus at $4 \mathrm{mg} /$ day. The patient was discharged on the $14^{\text {th }} \mathrm{PO}$ day; however, on the $31^{\text {st }} \mathrm{PO}$ day, he exhibited sudden dyspnea, and arrived at the emergency room in cardiorespiratory arrest, being unresponsive to resuscitation attempts. The autopsy showed an apparently healthy hepatic graft, without signs of hepatic cysts or other changes to the peritoneal cavity, suggesting pulmonary embolism as a cause of death.

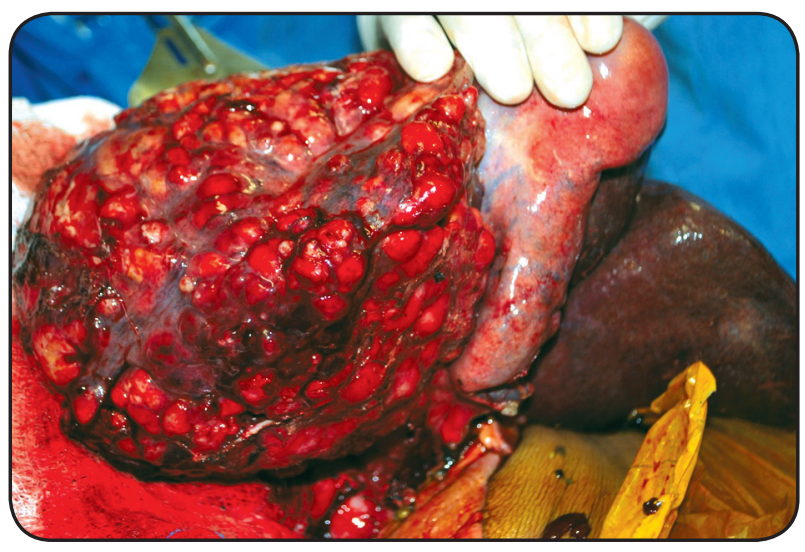

FIGURE 2 - Intraoperative view of the liver showing multiple cysts, occupying the right and left hepatic lobes and the hepatic hilum.

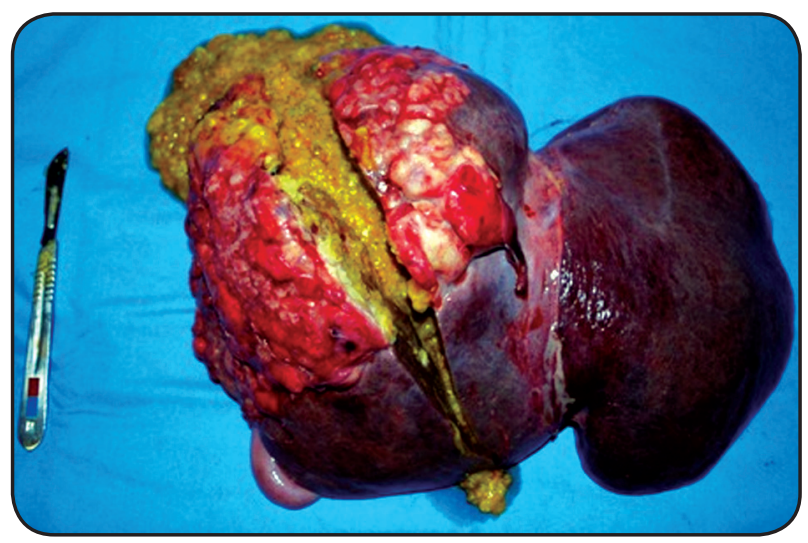

FIGURE 3 - Macroscopic appearance of explanted liver, showing multiple cysts with cavities filled with amorphous necrotic material.

\section{DISCUSSION}

Surgical resection is usually performed in cases of PE in which the cysts are small, allowing for adequate biliary drainage, or when chemotherapy fails. However, PE tends to be diagnosed late, when invasion and necrosis of hepatic tissues and vessels, infection of biliary ducts, and dissemination by contiguity has already begun. In addition, necrosis of biliary tissues, the inferior vena cava and the diaphragm can occur. Despite the high risk of undetected parasite dissemination in the intra-operative stage or during imaging, and the risk of PO complications, LT provides better survival results, mainly in cases of advanced disease progression. In addition, immunosuppression can favor the growth of remaining larvae after LT, which then favors disease recurrence ${ }^{10}$. Our patient's outcome after hospital discharge, until his sudden death from likely pulmonary embolism, has been described by other authors who performed transplantation for alveolar echinococcosis ${ }^{7}$. Liver transplantation can be considered as an alternative for patients in whom surgical resection cannot be performed due to disease progression, which may lead to very severe complications. Our report of the first LT case in a PE patient, caused by Echinococcus vogeli, demonstrates its technical feasibility with a good operative outcome, making it an interesting and viable alternative for treating advanced hydatidosis in Brazil.

\section{REFERENCES}

1. Moraes MAP, Sobreira MN, Medeiros Filho P, Tavares AC, Gomes MI. Polycystic hydatidosis: casual finding of calcified hydatid cyst simulating mesenteric neoplasm. Rev Soc Bras Med Trop 2003; 36:519-521.

2. Pastore R, Vitali LH, Weirich J, Tojal AC, Macedo VO, Prata A. Polycystic hydatic disease: report of two cases from the city of Sena Madureira, Acre, in Brazilian Amazon. Rev Soc Bras Med Trop 2003; 36:97-101.

3. D'Alessandro A, Rausch RL. New Aspects of Neotropical Polycystic (Echinococcus vogeli) and Unicystic (Echinococcus oligarthrus) Echinococcosis. Clin Microbiol Rev 2008; 21: 380-401.

4. Soares MC, Moreira-Silva CA, Alves MM, Nunes HM, Amaral IA, Móia LJ, et al. Polycystic echinococcosis in the Eastern Brazilian Amazon: an update. Rev Soc Bras Med Trop 2004; 37 (supl II):75-83.

5. Eckert J, Deplazes P. Biological, Epidemiological, and Clinical Aspects of Echinococcosis, a Zoonosis of Increasing Concern. Clin Microbiol 2004; 17:107-135.

6. Siqueira NG, Almeida FB, Chalub SR, Machado-Silva JR, Rodrigues-Silva R. Successful outcome of hepatic polycystic echinococcosis managed with surgery and chemotherapy. Trans R Soc Trop Med Hyg 2007; 101:624-626.

7. Bresson-Hadni S, Koch S, Miguet JP, Gillet M, Mantion GA, Heyd B, et al. Indications and results of liver transplantation for Echinococcus alveolar infection: an overview. Langenbecks Arch Surg 2003; 388:231-238.

8. Li F, Yang M, Li B, Yan L, Zen Y, Wen T, et al. Initial clinical results of orthotopic liver transplantation for hepatic alveolar echinococcosis. Liver Transpl 2007; 13:924-926.

9. Koch S, Bresson-Hadni S, Miguet JP, Crumbach JP, Gillet M, Mantion GA, et al. Experience of liver transplantation for incurable alveolar echinococcosis: a 45-case European collaborative report. Transplantation 2003; 75:856-863.

10. Yagci G, Ustunsoz B, Kaymakcioglu N, Bozlar U, Gorgulu S, Simsek A, et al. Results of surgical, laparoscopic, and percutaneous treatment for hydatid disease of the liver: 10 years experience with 355 patients. World J Surg 2005; 29:1670-1679. 